\title{
Synthesis, Spectral, Electrochemical and Theoretical Investigation of indolo[2,3-b]quinoxaline dyes derived from Anthraquinone for $n$-type materials
}

\author{
BHARAT K SHARMA ${ }^{\mathrm{a}}$, AZAM M SHAIKH ${ }^{\mathrm{a}}$, SAJEEV CHACKO ${ }^{\mathrm{b}}$ and RAJESH M KAMBLE ${ }^{\mathrm{a}, *}$ \\ ${ }^{a}$ Department of Chemistry, University of Mumbai, Santacruz (E), Mumbai, 400 098, India \\ ${ }^{b}$ Department of Physics, University of Mumbai, Santacruz (E), Mumbai, 400 098, India \\ Email: kamblerm@chem.mu.ac.in
}

MS received 6 January 2017; revised 10 February 2017; accepted 18 February 2017

\begin{abstract}
A series of five novel dyes based on indolo[2,3- $b$ ] quinoxaline skeleton, derived from anthraquinone, have been synthesized through cyclo-condensation reaction in good yield. The photophysical, electrochemical and thermal properties along with computed HOMO-LUMO energy levels were studied for the synthesized compounds. Their absorption and photoluminescence properties were investigated in various solvents and in neat solid film and found to possess characteristic electronic absorption and emission spectra which strongly depend on the nature of solvents used. Compounds show intramolecular charge transfer transitions (ICT) in the range of 501-561 nm with high molar absorption coefficient $(\varepsilon)$. These indoloquinoxaline derivatives emit in the range of $580-648 \mathrm{~nm}$ in solutions and $672-700 \mathrm{~nm}$ (red region) in neat solid films. Electrochemical data indicate that the dyes possess relatively low-lying LUMO levels in the range -3.29 to $-3.43 \mathrm{eV}$. The thermal stability observed for these compounds suggests their use under ambient conditions. The in-built donoracceptor architecture and HOMO-LUMO energies were further rationalized using DFT calculations. This study suggests that these compounds have potential to be used as $n$-type materials for optoelectronic devices.
\end{abstract}

Keywords. Indolo[2,3-b]quinoxaline; Intramolecular charge transfer (ICT); Donor-Acceptor architecture; $n$-type materials.

\section{Introduction}

Over the last few decades, research on small $\pi$-conjugated organic molecules has witnessed widespread attention for their technological applications in optoelectronic devices such as field-effect transistors, ${ }^{1}$ light emitting diodes ${ }^{2}$ and photovoltaic devices. ${ }^{3}$ The advantages of using small $\pi$-conjugated organic molecules are well-defined chemical structure and finite-size systems that can be obtained with high purity and solutionprocessability, ${ }^{4,5}$ thus offering the advantages to enable them to be printed or coated onto light weight, flexible substrates, which in turn allows for easy storage, transportation and installation measures. ${ }^{6}$ Further advancement and growth of organic electronics towards commercialization is due to development of costeffective organic $\pi$-conjugated materials that can be readily accessed from raw materials, through a sustainable synthesis with easy purification. ${ }^{7}$ One of the key design principles for the construction of small $\pi$-conjugated molecule is using molecular materials featuring donor-acceptor (D-A) architecture. D-A

*For correspondence architecture has built-in intramolecular charge transfer that facilitates manipulation of electronic structure leading to small band gap semiconducting materials. ${ }^{8}$ D-A architecture can also extend conjugated systems with efficient photoinduced charge transfer and separation for photovoltaic devices ${ }^{9}$ and to bipolar charge transport materials for light-emitting diodes, ${ }^{10}$ lasers,,${ }^{11}$ and other applications. Altering in D-A structures have allowed the optical, ${ }^{12}$ nonlinear optical, ${ }^{13}$ redox, ${ }^{12,14}$ and electroluminescent ${ }^{15}$ properties to be tuned over a wide range. From this perspective we have synthesized a novel highly tuneable small $\pi$-conjugated donoracceptor molecule based on Indolo[2,3-b]quinoxaline (IQ). Indolo[2,3-b]quinoxaline (IQ) and their derivatives are very important class of nitrogen containing heterocyclic compounds and have been widely used in medicinal chemistry as an anti-viral, ${ }^{16}$ anti-cancer, ${ }^{17}$ anti-microbial, ${ }^{18}$ anti-bacterial ${ }^{19}$ agents and as photoinitiators. ${ }^{20,21}$ Recently, indolo[2,3-b]quinoxaline are also studied for their application in optoelectronic devices. ${ }^{22}$ (Chart S1, in Supporting Information).

Most of the indoloquinoxaline derivatives that have been synthesized and studied for optoelectronic application are functionalized over $8^{\text {th }}$ or $9^{\text {th }}$ position of 

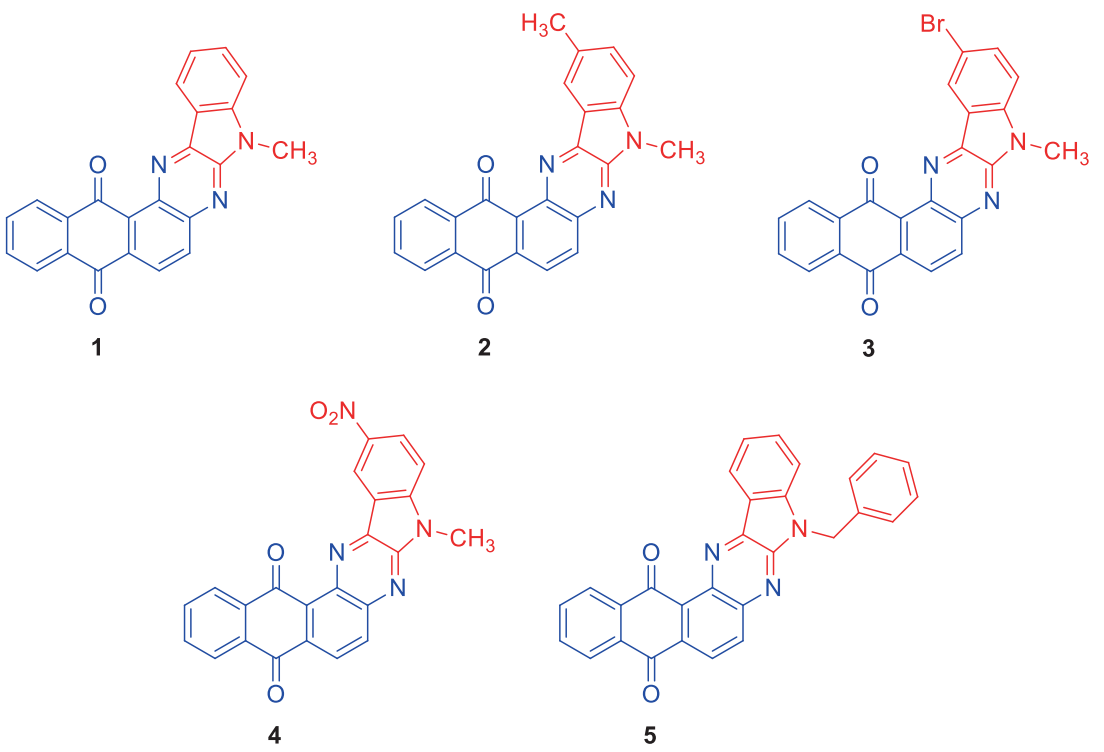

Chart 1. Synthesized indoloquinoxaline-based dyes.

indole subunit but substitution of groups affecting electronic properties of indoloquinoxaline molecule, at quinoxaline segment, are very rare and have not been studied extensively. In this paper, we report the study of a series of five new dyes, for which structures are based on indolo[2,3- $b$ ]quinoxaline (IQ) skeleton derived from anthraquinone (Chart 1) and their photophysical, electrochemical and thermal properties for their possible application in organic electronics.

Attempts were also made to understand the electronic structure of the newly synthesized dyes using DFT calculations. Synthesis and selection of the molecule is based on the consideration that the indoloquinoxaline segment is a built-in donor-acceptor chromophore as it contains the electron-rich indole unit fused with the electron-deficient quinoxaline moiety. ${ }^{22 a}$ Also, IQs are known for their strong solvent-dependent photophysical properties showing large fluorescence red shifts upon passing from non-polar to polar solvents and protic solvents at room temperature. ${ }^{21}$ Moreover, the introduction of more electronegative napthaquinone moiety into the indoloquinoxaline core rearranges the donor-acceptor unit in the newly synthesized molecules. We expect that the optoelectronic properties of the synthesized dyes can be tuned by introducing electron-donating $\left(-\mathrm{CH}_{3}\right)$ and electron-withdrawing $\left(-\mathrm{Br},-\mathrm{NO}_{2}\right)$ substituents.

\section{Experimental}

\subsection{Materials and Methods}

All the reagents were purchased from commercial sources (Sigma Aldrich and Alfa Aesar) and were used without further purification. The organic solvents were of analytical or spectroscopic grade and were dried and freshly distilled using the standard procedures whenever anhydrous solvents were required. ${ }^{1} \mathrm{H}-\mathrm{NMR}(600 \mathrm{MHz})$ spectra were recorded on a Varian $600 \mathrm{MHz}$ spectrometer with tetramethylsilane (TMS) as internal reference and residual $\mathrm{CHCl}_{3}$ in $\mathrm{CDCl}_{3}$ as reference ${ }^{13} \mathrm{C}$-NMR $(75 \mathrm{MHz})$ spectra were recorded on a Bruker Avance II $300 \mathrm{MHz}$ Ultrashield spectrometer with tetramethylsilane (TMS) as internal reference and residual $\mathrm{CHCl}_{3}$ in $\mathrm{CDCl}_{3}$ and DMSO- $\mathrm{d}_{6}$ as reference. Fourier transform infrared (FT-IR) spectra were recorded on a Perkin Elmer Frontier 91579. Mass spectrometric measurements were recorded using MALDI-TOF (Bruker). Melting points of the products were determined by differential scanning calorimeter on Stare ${ }^{\mathrm{e}}$ system Mettler Toledo DSC. Cyclic voltammetry and differential pulse voltammetry were carried out on a computer controlled PalmSens 3 potentiostat/galvanostat. Typically, a three electrode cell equipped with a glassy carbon working electrode, $\mathrm{Ag} / \mathrm{AgCl}$ (nonaqueous) reference electrode and platinum $(\mathrm{Pt})$ wire as counter electrode were employed. The measurements were carried at room temperature in anhydrous acetonitrile with tetrabutyl ammonium hexafluorophosphate solution $(0.1 \mathrm{M})$ as supporting electrolyte with scan rate of $100 \mathrm{mV} \mathrm{s}^{-1}$. The potential of $\mathrm{Ag} / \mathrm{AgCl}$ reference electrode was calibrated by using ferrocene/ferrocenium redox couple. Absorption and fluorescence data were acquired using $\sim 10^{-5} \mathrm{M}$ solutions of 1-5. UV-Visible spectra were recorded on SHIMADZU U.V-A114548 and fluorescence studies were done on Horiba Fluorolog 3 at room temperature. The fluorescence quantum yields $\left(\Phi_{\mathrm{F}}\right)$ were calculated relative to tetraphenylporphyrin $\left(\Phi_{\mathrm{F}}=0.12\right) .{ }^{23}$ The neat solid-films of compounds $\mathbf{1}-\mathbf{5}$ were prepared by drop cast method using $\sim 6 \mathrm{mg} \mathrm{mL}^{-1}$ of the sample in acetone. Quartz substrate was used for neat solid film studies. Thermal studies were performed under inert atmosphere. The thermo gravimetric analysis (TGA) was performed using Perkin Elmer Pyris Diamond TG/DTA with a heating rate of $10^{\circ} \mathrm{C} \mathrm{min}^{-1}$ under nitrogen atmosphere. 
Computational studies were performed using Gaussian 03 software package and the structures were optimized in gaseous state using B3LYP as an exchange correlation functional with 6-311G basis set.

\subsection{Synthesis}

The synthesis of target compounds is shown in Scheme 1. The synthesis of molecules $\mathbf{1 - 5}$ were completed in two steps. Firstly, isatin derivatives were alkylated at their N-position to increase the solubility of the target molecules and later, the 5-methylated isatin derivatives were reacted with 1,2diaminoathraquinone in acetic acid for $1-2 \mathrm{~h}$ to produce the desired cyclocondensed product. The five target compounds were obtained in good yield (72-78\%) as deep red solids. The identity and purity of all the new compounds were confirmed by several characterization methods such as ${ }^{1} \mathrm{H}-\mathrm{NMR},{ }^{13} \mathrm{C}-\mathrm{NMR}, \mathrm{MALDI}-\mathrm{TOF}$ mass, FTIR etc.

2.2a General procedure for methylation and benzylation: Methylation and benzylation of isatin and its derivatives were done by reported procedures. ${ }^{24}$ To a mixture of isatin $(1.61 \mathrm{~g}, 10 \mathrm{mmol})$ in anhydrous DMF $(30 \mathrm{~mL})$ was added $\mathrm{K}_{2} \mathrm{CO}_{3}(3.45 \mathrm{~g}, 25 \mathrm{mmol})$ at room temperature. After $30 \mathrm{~min}$, iodomethane $(1.25 \mathrm{~mL}, 20 \mathrm{mmol})$ or benzylbromide $(2.37 \mathrm{~mL}, 20 \mathrm{mmol})$ was added, and stirring was continued at room temperature for $12 \mathrm{~h}$. The reaction mixture was quenched by slow addition of water. The resulting solid obtained by vacuum filtration was washed thoroughly with water to give $\mathrm{N}$-methylated and $\mathrm{N}$-benzylated product of isatin and its derivatives.

2.2b General method of synthesis of compounds 1-5: In a two-necked round bottom flask equipped with reflux condenser and magnetic stirrer 1,2-diaminoanthraquinone $(1.0 \mathrm{mmol})$ and 5 -Substituted-1-methyl- $1 \mathrm{H}$-Indole-2,3-dione $(1.2 \mathrm{mmol})$ were dissolved in glacial acetic acid $(10 \mathrm{~mL})$. The reaction mixture was thoroughly stirred at the reflux temperature for $1-2 \mathrm{~h}$. Reaction mixture was cooled to room temperature and neutralized with sodium hydrogen carbonate to $\mathrm{pH} 7$. The resulting solid obtained by vacuum filtration was washed thoroughly with $\mathrm{H}_{2} \mathrm{O}$ and left overnight for air drying. The crude product obtained was further purified by silica gelcolumn chromatography.

2.2c 9-methyl-5H-indolo[2,3-b]naphtho[2,3-f]quinoxaline-5,15(9H)-dione 1: A mixture of 1,2-diaminoanthraquinone $(0.28 \mathrm{~g}, 1.0 \mathrm{mmol})$ and $1-$ methyl-5H-indoline-2, 3 -dione $(0.19 \mathrm{~g}, 1.2 \mathrm{mmol})$ were reacted in glacial acetic acid $(10 \mathrm{~mL})$ as mentioned in the general method. The crude solid thus obtained was purified by column chromatography using hexane/chloroform 10/90 to obtain a deep red solid. Yield: $72.8 \%$ (0.26 g); M.p: $239^{\circ} \mathrm{C}$; FTIR (KBr, v/ $\left.\mathrm{cm}^{-1}\right)$ : 3426.74, 3237.72, 1705.53, 1651.62, 1489.18, 1293.65, 1104.73, 1001.62, 814.00, 713.84; ${ }^{1} \mathrm{H}-\mathrm{NMR}(600 \mathrm{MHz}$, $\left.\mathrm{CDCl}_{3} 25^{\circ} \mathrm{C}\right) \delta$, ppm: $3.23\left(\mathrm{~s}, 3 \mathrm{H}, \mathrm{CH}_{3}\right), 6.70(\mathrm{~d}, 1 \mathrm{H}, \mathrm{ArH}, J$ $=7.2 \mathrm{~Hz}), 6.88(\mathrm{~d}, 1 \mathrm{H}, \mathrm{ArH}, J=8.4 \mathrm{~Hz}), 7.15(\mathrm{t}, 1 \mathrm{H}, \mathrm{ArH}, J$ $=7.2 \mathrm{~Hz}), 7.43(\mathrm{t}, 1 \mathrm{H}, \mathrm{ArH}, J=7.8 \mathrm{~Hz}), 7.54(\mathrm{~d}, 1 \mathrm{H}, \mathrm{ArH}$, $J=7.2 \mathrm{~Hz}), 7.73(\mathrm{~m}, 2 \mathrm{H}, \mathrm{ArH}), 7.81$ (s, 1H, ArH), 8.21 (d, $1 \mathrm{H}, \operatorname{ArH}, J=7.2 \mathrm{~Hz}), 8.33$ (d, 1H, ArH, $J=7.2 \mathrm{~Hz}$ ); ${ }^{13} \mathrm{CNMR}\left(75 \mathrm{MHz}, \mathrm{DMSO}-\mathrm{d}_{6} 25^{\circ} \mathrm{C}\right) \delta$, ppm: 26.28, 108.64, $109.02,121.37,122.75,122.98,124.98,125.81,126.48$, $128.32,128.57,130.90,133.09,133.26,133.79,134.42$, $135.99,139.22,142.79,143.76,147.82,179.70,182.00$; MALDI-TOF: mass calcd for $\mathrm{C}_{23} \mathrm{H}_{13} \mathrm{~N}_{3} \mathrm{O}_{2}$ [M+]: 363.37; found: 363.18; anal. Calcd for $\mathrm{C}_{23} \mathrm{H}_{13} \mathrm{~N}_{3} \mathrm{O}_{2}$ : C, 76.02; $\mathrm{H}$, 3.61, N, 11.56\%. Found: C, 76.35; H, 3.58; N, $11.52 \%$.

2.2d 9,12-dimethyl-5H-indolo[2,3-b]naphtho[2,3-f] quinoxaline-5,15(9H)-dione 2: A mixture of 1,2diaminoanthraquinone $(0.28 \mathrm{~g}, 1.0 \mathrm{mmol})$ and $1,5-$ dimethylindoline-2, 3-dione $(0.21 \mathrm{~g}, 1.2 \mathrm{mmol})$ were reacted in glacial acetic acid $(10 \mathrm{~mL})$ as mentioned in the general method. The crude solid thus obtained was purified by column chromatography using chloroform to obtain a deep red solid. Yield: $78.4 \%(0.29 \mathrm{~g})$; M.p: $273^{\circ} \mathrm{C}$; FT-IR $(\mathrm{KBr}$, $\left.v / \mathrm{cm}^{-1}\right)$ : 3425.39, 3238.60, 1711.27, 1650.07, 1488.03, 1321.03 1291.80, 1095.13, 751.81, 714.17, 491.96; ${ }^{1} \mathrm{HNMR}$ $\left(600 \mathrm{MHz} \mathrm{CDCl}_{3} 25^{\circ} \mathrm{C}\right) \delta$, ppm: $2.33\left(\mathrm{~s}, 3 \mathrm{H}, \mathrm{CH}_{3}\right), 3.23(\mathrm{~s}$, $\left.3 \mathrm{H}, \mathrm{CH}_{3}\right), 6.69$ (d, 1H, ArH, $\left.J=8.4 \mathrm{~Hz}\right), 6.77$ (d, 1H, ArH,

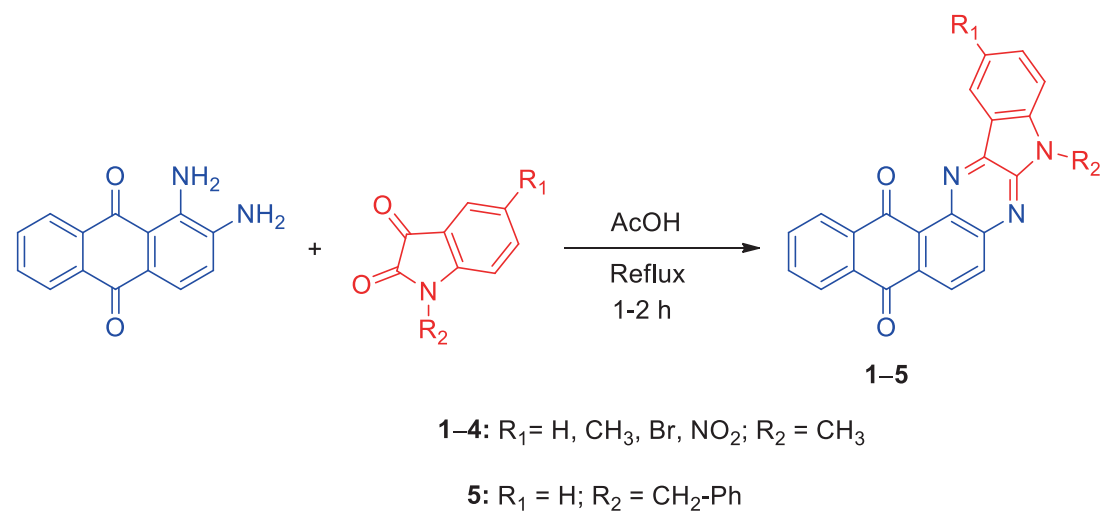

Scheme 1. Scheme for the preparation of indoloquinoxaline dyes 1-5. 
$J=7.8 \mathrm{~Hz}), 7.22(\mathrm{t}, 1 \mathrm{H}, \mathrm{ArH}, J=8.4 \mathrm{~Hz}), 7.36(\mathrm{~s}, 1 \mathrm{H}$, ArH), 7.75 (m, 2H, ArH), 7.79 (s, 1H, ArH,), 8.22 (d, 1H, $\mathrm{ArH}, J=7.2 \mathrm{~Hz}), 8.34$ (d, $1 \mathrm{H}, \mathrm{ArH}, J=7.8 \mathrm{~Hz}) ;{ }^{13} \mathrm{CNMR}$ (75 MHz, DMSO-d ${ }_{6} 25^{\circ} \mathrm{C}$ ) $\delta$, ppm: 20.33, 26.29, 108.56, $108.77,121.32,122.72,125.50,125.80,126.46,128.30$, $129.46,129.93,130.89,132.19,133.07,133.25,133.81$, 134.44, 141.28, 142.76, 147.80, 172.30, 179.65, 181.97; MALDI-TOF: mass calcd for $\mathrm{C}_{24} \mathrm{H}_{15} \mathrm{~N}_{3} \mathrm{O}_{2}[\mathrm{M}+]$ : 377.12; found: 378.21; anal. Calcd for $\mathrm{C}_{24} \mathrm{H}_{15} \mathrm{~N}_{3} \mathrm{O}_{2}$ : C, 76.38; $\mathrm{H}$, 4.01, N, 11.13\%. Found: C, 76.65; H, 3.88; N, 10.92\%.

2.2e 12-bromo-9-methyl-5H-indolo[2,3-b]naphtho [2,3-f]quinoxaline-5,15(9H)-dione 3: A mixture of 1,2diaminoanthraquinone $(0.28 \mathrm{~g}, 1.0 \mathrm{mmol})$ and 1-methyl5-bromo-indoline-2,3-dione $(0.28 \mathrm{~g}, 1.2 \mathrm{mmol})$ were reacted in glacial acetic acid $(10 \mathrm{~mL})$ as mentioned in the general method. The crude solid thus obtained was purified by column chromatography using chloroform to obtain a deep red solid. Yield: $73.2 \%(0.32 \mathrm{~g})$; M.p: $278^{\circ} \mathrm{C}$; FTIR $\left(\mathrm{KBr}, v / \mathrm{cm}^{-1}\right): 3417.20,3229.61,1710.49,1658.32$, 1493.24, 1364.97, 1275.99, 1167.77, 762.94, 714.04; ${ }^{1} \mathrm{HNMR}\left(600 \mathrm{MHz}, \mathrm{CDCl}_{3} 25^{\circ} \mathrm{C}\right) \delta$, ppm: $3.22(\mathrm{~s}, 3 \mathrm{H}$, $\left.\mathrm{CH}_{3}\right), 6.72(\mathrm{~d}, 1 \mathrm{H}, \mathrm{ArH}, J=7.8 \mathrm{~Hz}), 6.78(\mathrm{~d}, 1 \mathrm{H}, \mathrm{ArH}, J=$ $8.4 \mathrm{~Hz}), 7.56$ (d, 1H, ArH, $J=8.4 \mathrm{~Hz}), 7.68$ (s, 1H, ArH), 7.75 (m, 3H, ArH), 8.22 (d, 1H, ArH, $J=7.8 \mathrm{~Hz}), 8.34$ (d, $1 \mathrm{H}, \mathrm{ArH}, J=7.8 \mathrm{~Hz}) ;{ }^{13} \mathrm{CNMR}\left(75 \mathrm{MHz}, \mathrm{DMSO}-\mathrm{d}_{6} 25^{\circ} \mathrm{C}\right)$ $\delta$, ppm: 26.40, 108.87, 111.14, 114.63, 121.58, 122.26, $122.65,125.82,126.49,127.72,128.86,127.72,130.71$, 133.12 , 133.31, 133.42, 133.76, 134.38, 142.51, 143.04, 147.54, 179.74, 182.07; MALDI-TOF: mass calcd for $\mathrm{C}_{23} \mathrm{H}_{12} \mathrm{BrN}_{3} \mathrm{O}_{2}[\mathrm{M}+]$ : 441.01; found: 442.89; anal. Calcd for $\mathrm{C}_{23} \mathrm{H}_{12} \mathrm{BrN}_{3} \mathrm{O}_{2}$ : C, 62.46; H, 2.73, N, 9.50\%. Found: C, $62.23 ; \mathrm{H}, 2.58 ; \mathrm{N}, 9.32 \%$.

2.2f 9-methyl-12-nitro-5H-indolo[2,3-b]naphtha[2, 3-f]quinoxaline-5,15(9H)-dione 4: A mixture of 1,2diaminoanthraquinone $(0.28 \mathrm{~g}, 1.0 \mathrm{mmol})$ and $1-$ methyl5 -nitro-indoline-2, 3-dione $(0.24 \mathrm{~g}, 1.2 \mathrm{mmol})$ were reacted in glacial acetic acid $(10 \mathrm{~mL})$ as mentioned in the general method. The crude solid thus obtained was purified by column chromatography using chloroform/ethyl acetate 90/10 to obtain a deep red solid. Yield: $74.7 \%(0.30 \mathrm{~g})$; M.p: $289^{\circ} \mathrm{C}$; FT-IR $\left(\mathrm{KBr}, v / \mathrm{cm}^{-1}\right)$ : 3417.20, 3229.61, 1621.50, 1483.62, 1275.99, 1019.46, 704.42, 556.11; ${ }^{1} \mathrm{HNMR}(600$ $\left.\mathrm{MHz}, \mathrm{CDCl}_{3} 25^{\circ} \mathrm{C}\right) \delta$, ppm: $3.18\left(\mathrm{~s}, 3 \mathrm{H}, \mathrm{CH}_{3}\right), 6.67(\mathrm{~d}, 1 \mathrm{H}$, $\mathrm{ArH}, J=7.8 \mathrm{~Hz}), 6.73$ (d, 1H, ArH, $J=8.4 \mathrm{~Hz}), 7.52$ (d, 1H, ArH, $J=8.4 \mathrm{~Hz}), 7.63$ (s, 1H, ArH), $7.71(\mathrm{~m}, 3 \mathrm{H}$, ArH), 8.18 (d, 1H, ArH, $J=7.8 \mathrm{~Hz}$ ), 8.39 (d, 1H, ArH, $J$ $=7.8 \mathrm{~Hz}) ;{ }^{13} \mathrm{CNMR}\left(75 \mathrm{MHz}, \mathrm{DMSO}-\mathrm{d}_{6} 25^{\circ} \mathrm{C}\right) \delta, \mathrm{ppm}:$ $34.85,108.50,109.65,110.88,111.14,111.88,112.50$, $122.59,125.42,127.31,128.12,128.72,130.85,131.59$, $138.09,139.26,139.93,142.04,147.53,152.14,152.63$, 184.29, 186.84; MALDI-TOF: mass calcd for $\mathrm{C}_{23} \mathrm{H}_{12} \mathrm{~N}_{4} \mathrm{O}_{4}$ [M+ ]: 408.09; found: 409.63; anal. Calcd for $\mathrm{C}_{23} \mathrm{H}_{12} \mathrm{~N}_{4} \mathrm{O}_{4}$ : C, 67.65; H, 2.96, N, 13.72\%. Found: C, 67.46; H, 3.18; N, $13.59 \%$.
$2.2 \mathrm{~g}$ 9-benzyl-5H-indolo[2,3-b]naphtho[2,3-f]quinoxaline-5,15(9H)-dione 5: A mixture of 1,2-diaminoanthraquinone $(0.28 \mathrm{~g}, 1.0 \mathrm{mmol})$ and 1-benzylindoline-2, 3 -dione $(0.28 \mathrm{~g}, 1.2 \mathrm{mmol})$ were reacted in glacial acetic acid $(10 \mathrm{~mL})$ as mentioned in the general method. The crude solid thus obtained was purified by column chromatography using hexane/chloroform 10/90 to obtain a deep red solid. Yield: $71.6 \%$ (0.31 g); M.p: $277^{\circ} \mathrm{C}$; FT-IR (KBr, v/cm ${ }^{-1}$ ): 3423.69 , 3234.36, 1712.89, 1484.71, 1293.75, 980.76, 712.96; ${ }^{1} \mathrm{H}$ and ${ }^{13} \mathrm{C}-\mathrm{NMR}$ could not be obtained because of very poor solubility of this compound in common organic solvents; MALDI-TOF: mass calcd for $\mathrm{C}_{29} \mathrm{H}_{17} \mathrm{~N}_{3} \mathrm{O}_{2}$ [M+ ]: 439.13; found: 439.16; anal. Calcd for $\mathrm{C}_{23} \mathrm{H}_{12} \mathrm{~N}_{4} \mathrm{O}_{4}$ : C, 79.26; $\mathrm{H}$, $3.90 ;$ N, 9.56\%. Found: C, 78.92; H, 4.24; N, 9.73\%.

\section{Results and Discussion}

\subsection{Photophysical Properties}

The photophysical behavior of compounds $\mathbf{1 - 5}$ were examined by measuring absorption and emission spectra in neat solid films and in solvents of varying polarity, viz., toluene, dichloromethane, ethylacetate, acetonitrile, ethanol and dimethylsulphoxide (DMSO). The aim of this study was to explore effects of solvent polarity on photophysical properties of the dyes and to correlate these effects with their structures. The pertinent data are listed in Table 1 and Table (S1-S5) (Supporting Information). The absorption and emission spectra recorded for the dyes $\mathbf{1 - 5}$ in dichloromethane are shown in Figure 1. The absorption spectra of core indolo[2,3-b]quinoxaline molecule is known to exhibit well-resolved absorption peaks at 290, 330, 355 and $420 \mathrm{~nm}^{22 \mathrm{a}, \mathrm{d}}$ The longer wavelength absorption $(420 \mathrm{~nm})$ corresponds to the charge transfer from indole to quinoxaline segment while the shorter wavelength bands originate from the $\pi-\pi *$ and $n-\pi *$ transitions.

Invariably all the molecules exhibit different absorption profiles compared with that of core indolo[2,3b]quinoxaline molecule and feature three primary absorption bands at $\sim 262, \sim 322$ and $\sim 510 \mathrm{~nm}$. Among these transitions, the two at higher energy absorptions are probably originating from localized electronic excitations by the entire molecule due to $\pi-\pi^{*}$ and $n-\pi *$ transitions, while the lower energy band is attributable to the charge transfer transition (ICT) from electron donating indole unit to electron accepting naphtho[2,3$f$ ]quinoxaline-7,12-dione segment (Figure 1, Table 1). A deep orange-red emission is observed for all of the derivatives in dichloromethane (Figure 1).

Effect of the nature of substitution $\left(\mathrm{R}_{1}=\mathrm{CH}_{3}, \mathrm{Br}\right.$, $\mathrm{NO}_{2}$ ) attached to these dyes on photophysical properties is exhibited as shift in the long-wavelength ICT absorption band and emission maximum in $\mathbf{1 - 5}$. The presence 
Table 1. Photophysical data of compounds 1-5 in DCM.

\begin{tabular}{lccccccc}
\hline Compound & $\lambda_{\mathrm{abs}},{ }^{\mathrm{a}} \mathrm{nm}\left(\log \varepsilon, \mathrm{M}^{-1} \mathrm{~cm}^{-1}\right)$ & $\lambda_{\mathrm{em}}^{\mathrm{a}}, \mathrm{nm}$ & $\lambda_{\mathrm{abs}},{ }^{\mathrm{b}} \mathrm{nm}$ & $\lambda_{\mathrm{em}}^{\mathrm{b}}, \mathrm{nm}$ & Stokes shift, ${ }^{\mathrm{a}} \mathrm{cm}^{-1}$ & $\Phi_{f}^{c}$ & $E_{g}^{d}, \mathrm{eV}$ \\
\hline $\mathbf{1}$ & $252(5.11), 312(4.14), 501(4.46)$ & 589 & $273,451,634$ & 672 & 2982 & 0.041 & 2.21 \\
$\mathbf{2}$ & $261(5.07), 322(4.14), 504(4.35)$ & 592 & $302,482,665$ & 688 & 2949 & 0.051 & 2.23 \\
$\mathbf{3}$ & $262(5.07), 322(4.14), 508(4.38)$ & 598 & 273,555 & 692 & 2962 & 0.041 & 2.21 \\
$\mathbf{4}$ & $263(5.34), 333(4.19), 529(4.74)$ & 612 & 269,565 & 700 & 2563 & 0.022 & 2.16 \\
$\mathbf{5}$ & $262(5.11), 322(4.19), 506(4.44)$ & 598 & - & - & 3040 & 0.036 & 2.16 \\
\hline
\end{tabular}

${ }^{\mathrm{a}}$ In DCM; ${ }^{\mathrm{b}}$ In neat solid film; ${ }^{\mathrm{c}}$ Quantum yield w.r.t tetraphenylporphyrin $\left(\Phi_{\mathrm{F}}=0.12\right)$; ${ }^{\mathrm{d}}$ Optical band gap estimated using emission and excitation spectra in toluene.
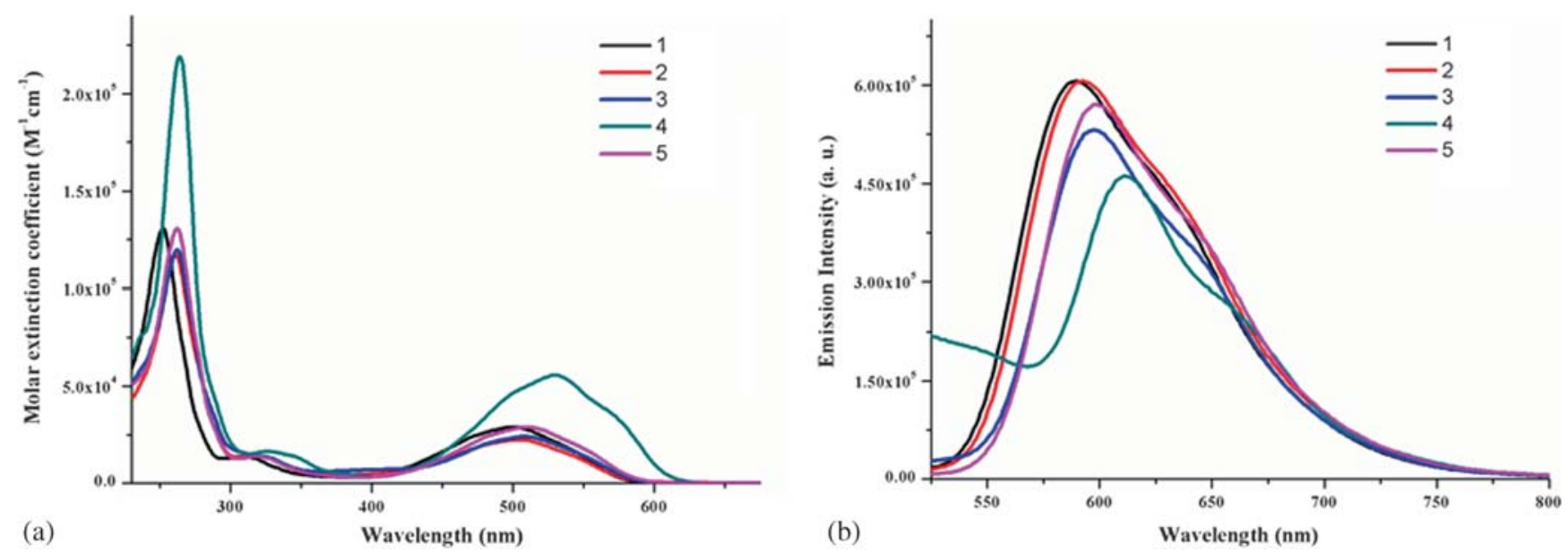

Figure 1. Absorption (a) and emission (b) spectra of compounds 1-5 in DCM.

of electron withdrawing $-\mathrm{NO}_{2}$ substituent in compound 4 showed bathochromic shift in ICT and emission maximum compared to that of $\mathbf{1}$ having no substitution, while the presence of electron donating $-\mathrm{CH}_{3}$ group in $\mathbf{2}$ showed a comparative blue shift compared to that of 1 in both absorption and emission spectra. While the substitution of benzyl group at indole nitrogen in $\mathbf{5}$ did not show any major change in photophysical properties compared to 1 . This effect of substitution on the photophysical properties can be correlated with the observations seen in the DFT studies as change in HOMO molecular orbitals after substitution compared with HOMO of 1; whereas, LUMO orbitals are not found to be affected by the effect of substituent in the dyes.

In order to further probe the nature of the ICT and emission transitions in these dyes, we have measured the solvent dependence of the absorption and emission spectra of 1-5. The solvent effect in 1-5 is expressed as positive solvatochromism; i.e., bathochromic shift in ICT transitions by $\sim 40 \mathrm{~nm}$ by varying the polarity of solvent (Figure 2). To our surprise, a prominent high energy electronic excitation at $\sim 390 \mathrm{~nm}$ was observed in toluene and ethyl acetate for $\mathbf{1}, \mathbf{2}$ and $\mathbf{3}$. The emission maxima show pronounced bathchromic shift of $\sim 60 \mathrm{~nm}$ on increasing the polarity of the solvent as illustrated for compound $\mathbf{2}$ in Figure 2. The most red shifted emission for each dye was observed for DMSO solution with substantial reduction in the fluorescence intensity (see Supplementary Information).

The absorption ICT and emission characteristics were found to be dependent on the dielectric constant of the medium. With increase in solvent polarity, the excited-state structure of the dye becomes more stabilized than the ground state, since the excited state is more dipolar than the ground state which results in stabilization of the dye molecules in the solvent like DMSO having high dielectric constant and thus demonstrating a decrease in the energy level of the excited state. ${ }^{25}$ Also, the excited state appears to be more polar than the ground state in view of the large Stokes shifts reaching to values of $\sim 2950 \mathrm{~cm}^{-1}$ as observed for these compounds (Table 1). A reasonably large Stokes shift is also desirable for the application in electroactive devices as it ensures the reduction of self-absorption.

Moreover, anomalous behavior of the dyes was observed in the polar protic solvents, like ethanol, with increase in absorption, emission maxima and Stokes shift and decrease in band gap. It is explainable based on the earlier reported properties of indoloquinoxalines (IQ) as the mechanism of $\mathrm{S}_{1}$ radiationless depopulation 

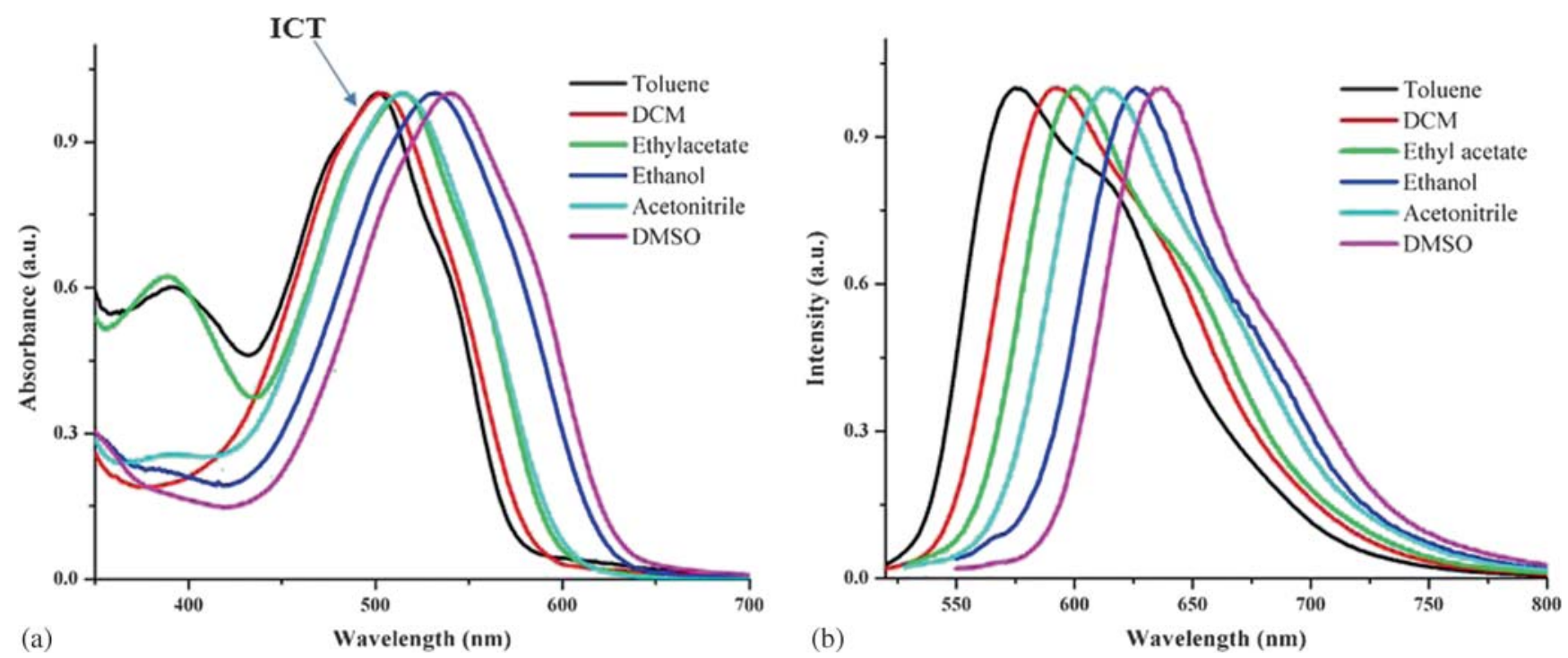

Figure 2. Normalized absorption (a) and emission (b) spectra of compound 2 in various solvents.

Table 2. Electrochemical and thermogravimetric analysis (TGA) data of compounds 1-5.

\begin{tabular}{lccccccc}
\hline Compound & $\mathrm{E}_{\mathrm{ox}}(\mathrm{V})^{\mathrm{a}}$ & $\mathrm{E}_{\mathrm{red}}(\mathrm{V})^{\mathrm{b}}$ & $\mathrm{HOMO}^{\mathrm{c}}(\mathrm{eV})$ & $\mathrm{LUMO}^{\mathrm{d}}(\mathrm{eV})$ & $\mathrm{E}_{\mathrm{g}}^{\mathrm{e}}(\mathrm{eV})^{\mathrm{a}}$ & $\mathrm{T}_{\mathrm{m}}^{\mathrm{f}}\left({ }^{\circ} \mathrm{C}\right)$ & $\mathrm{T}_{\mathrm{d}}^{\mathrm{g}}\left({ }^{\circ} \mathrm{C}\right)$ \\
\hline $\mathbf{1}$ & $1.79,2.19$ & $-1.42,-2.38$ & -6.53 & -3.32 & 3.21 & 239 & 295 \\
$\mathbf{2}$ & 1.90 & $-1.55,-2.19$ & -6.64 & -3.19 & 3.45 & 273 & 292 \\
$\mathbf{3}$ & 1.94 & $-1.41,-2.56$ & -6.68 & -3.33 & 3.35 & 278 & 140 \\
$\mathbf{4}$ & $1.77,2.26$ & $-1.45,-2.01$ & -6.51 & -3.29 & 3.22 & 289 & 237 \\
$\mathbf{5}$ & $1.89,2.24$ & $-1.53,-2.19$ & -6.63 & -3.21 & 3.42 & 277 & 334 \\
\hline
\end{tabular}

${ }^{\mathrm{a}}$ Oxidation peak potential. ${ }^{\mathrm{b}}$ Reduction peak potential. ${ }^{\mathrm{c}} \mathrm{E}_{\mathrm{HOMO}}=-\left(\mathrm{E}_{\left[\mathrm{ox} \mathrm{vsFc} / \mathrm{Fc}^{+}\right]}+5.1\right) \mathrm{eV} .{ }^{\mathrm{d}} \mathrm{E}_{\mathrm{LUMO}}=-\left(\mathrm{E}_{\left[\mathrm{red} \mathrm{vs} \mathrm{Fc} / \mathrm{Fc}^{+}\right]}+5.1\right)$ $\mathrm{eV} .{ }^{\mathrm{e}} \mathrm{E}_{\mathrm{g}}^{\mathrm{cr}}=\mathrm{E}_{\mathrm{HOMO}}-\mathrm{E}_{\mathrm{LUMO}} \cdot{ }^{\mathrm{f}}$ Melting points determined by DSC. ${ }^{\mathrm{g}}$ Decomposition temperature obtained from the onset of derivative weight loss curve.

for these molecules are completely different in aprotic and protic solvents which could be explained as decrease in the radiative rates (inter-system crossing) and enhanced (fast) internal conversion from $\mathrm{S}_{1}(\pi-$ $\left.\pi^{*}\right)$ for the protic solvents. ${ }^{21}$

The quantum yields of dyes 1-5 are strongly dependent on the polarity of the solvent and the molecular structure and were found to be low, varying from 0.051 to 0.008 (Table 2) w.r.t tetraphenylporphyrin $\left(\Phi_{\mathrm{F}}=\right.$ $0.12){ }^{23}$ With increase in polarity of the solvent, the quantum yields of 1-5 were reduced. The presence of electron withdrawing $-\mathrm{NO}_{2}$ group in 4 results in decrease in quantum yield and band gap compared to the presence of electron donating $-\mathrm{CH}_{3}$ substituent in $\mathbf{2}$. Further, with increase in solvent polarity, optical band gap of the dyes reduces demonstrating greater stabilization of the dyes in the excited state by polar solvent molecules. Absorption and emission spectra of 15 in neat solid films revealed red-shifted absorption and emission bands compared to the spectra in solutions. It may be due to aggregation of molecules in the solid state. ${ }^{26}$ Compound $\mathbf{5}$ could not be used in thin film absorption and emission studies as it did not produce uniform neat solid film due to poor solubility in common organic solvents.

\subsection{Electrochemical Study}

The redox propensities of 1-5 were examined in acetonitrile solution and energy levels of the frontier orbitals determined by means of cyclic voltammetry (CV) and differential pulse voltammetry (DPV). The cyclic voltammograms of $\mathbf{1}-\mathbf{5}$ were recorded by using ferrocene as internal standard and these are shown in Figure 3. The pertinent parameters are collected in Table 2. The redox properties are nearly similar for all compounds. An irreversible first oxidation wave for 1-5 was observed in the range 1.79-1.94 V, probably originating from indole subunit. The oxidation potential of indole unit was found to be more positive than observed for core indoloquinoxaline molecule due to the presence of electron-withdrawing naphtho[2,3$f$ ] quinoxaline-7,12-dione segment. A second oxidation 

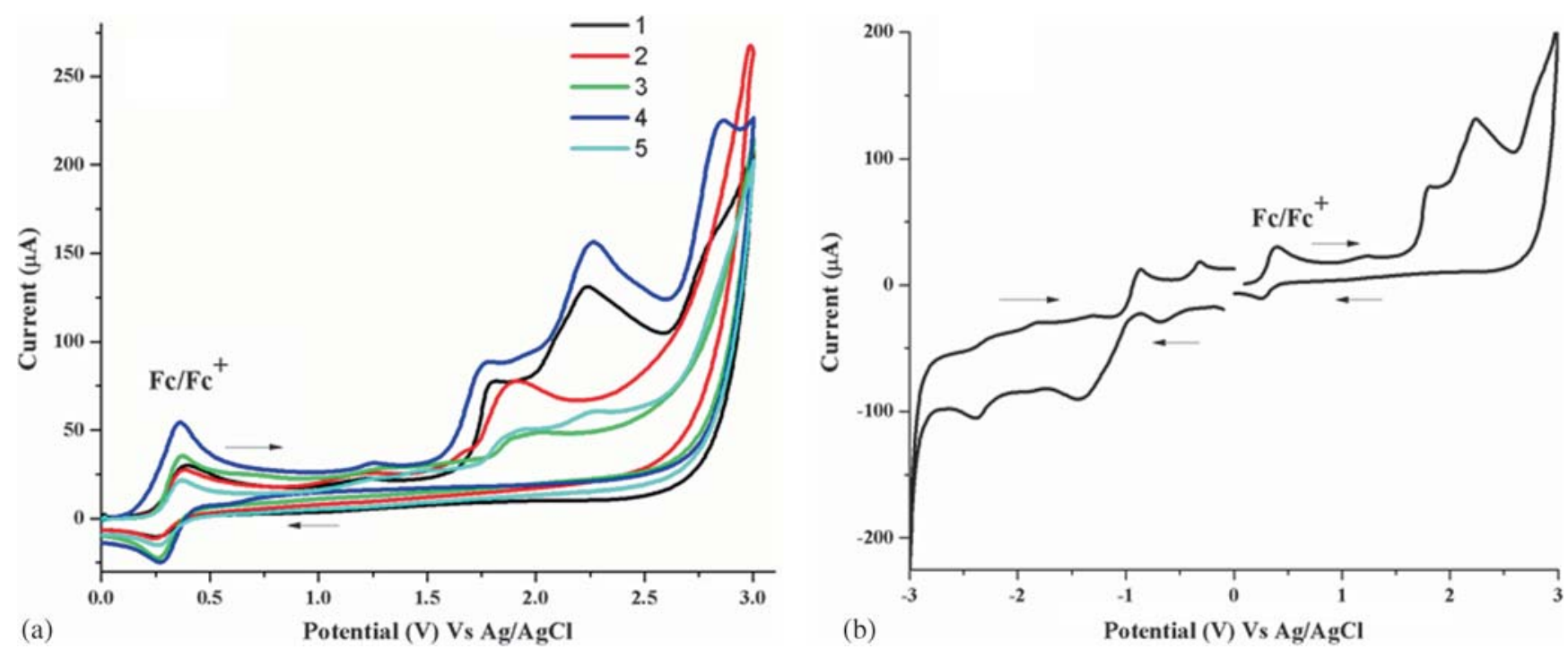

Figure 3. (a) Cyclic Voltammogram of compounds 1-5; (b) full scan of compound $\mathbf{1}$ in acetonitrile.

wave at higher oxidation potential was seen in range of 2.19-2.26 V for compounds $\mathbf{1}, \mathbf{4}$ and $\mathbf{5}$ which may be due to the oxidation of quinoxaline moiety. When scanning to negative potentials, all the molecules underwent a quasi-reversible reduction at -1.41 to $-1.51 \mathrm{~V}$ originating from the quinoxaline segment and an irreversible reduction at -2.01 to $-2.56 \mathrm{~V}$ which is typical reduction of carbonyl groups of anthraquinone. ${ }^{27,14 \mathrm{~b}}$ The reduction potential due to quinoxaline segment in these molecules is shifted to more negative value than those for simple quinoxaline derivatives ${ }^{22 f}$ which indicates the role of electron-withdrawing napthoquinone segment.

From the first oxidation and reduction potential, the HOMO and LUMO energy levels of 1-5 were calculated (Table 2) and were found in the range -6.51 to $-6.68 \mathrm{eV}$ and -3.29 to $-3.42 \mathrm{eV}$, respectively by setting $\mathrm{Fc} / \mathrm{Fc}_{\text {vac }}^{+}$at $-5.1 \mathrm{eV}$ vs. vacuum ${ }^{15,28 \mathrm{a}}$ indicating low lying LUMO energy levels. The low lying LUMO energy levels in the range -3.0 to $-4.0 \mathrm{eV}$ is essential for the efficiency and stability of n-type materials. ${ }^{29}$ The LUMO energy levels of the dyes 1-5 are found to be lower than that of the most widely used electron-transport (small n-type) materials; such as metal chelates like Alq3 (tris(8hydroxyquinoline)aluminium) $(\mathrm{LUMO}=3.10 \mathrm{eV})^{30}$ organic materials such as 2,4,7,9-tetraphenylpyrido $[2,3-g]$ quinolone $(\mathrm{LUMO}=3.10 \mathrm{eV})^{31}$ 2,5-di([1, 10-biphenyl]-4-yl)-1,1-dimethyl-3,4-diphenyl- $1 H$-silole $(\mathrm{LUMO}=3.30 \mathrm{eV})^{32}$ and some polymers such as polyquinoxalines $(\mathrm{LUMO}=3.0-3.24 \mathrm{eV})^{33}$ polyphenylquinoxalines andthiophene linked polyphenylquinoxalines (LUMO $=3.0-3.30 \mathrm{eV}),{ }^{34}$ thus making these molecules as potential candidates for electron-transport materials.

\subsection{Thermal Studies}

The thermal properties of the dyes were studied by both thermogravimetric analysis (TGA) and differential scanning calorimetry (DSC). The melting points $\left(\mathrm{T}_{\mathrm{m}}\right)$ of 1-5 were determined by DSC, displaying one sharp endothermic peak and were found in the range of 239$289^{\circ} \mathrm{C}$. The observed thermal stability data are compiled in Table 2. Decomposition temperature for these compounds was calculated using the onset of weight loss in TGA and found to be in the range of $216-363^{\circ} \mathrm{C}$ (corresponding to 5\% weight loss). TGA revealed that 1-5 are thermally stable materials, and the onset of the decomposition $\left(\mathrm{T}_{\mathrm{d}}\right)$ occurred above $230^{\circ} \mathrm{C}$, except compound $\mathbf{3}\left(140^{\circ} \mathrm{C}\right)$. Thermograms of $\mathbf{1}-\mathbf{5}$ are given in supplementary information. The order of thermal stability among compounds $\mathbf{1}-\mathbf{5}$ is $\mathbf{4}<\mathbf{2}<\mathbf{1}<\mathbf{3}<\mathbf{5}$. No glass transition temperature was observed in $\mathbf{1}-\mathbf{5}$.

\subsection{Computational study}

Quantum chemical calculations were performed using the Gaussian 03 software package ${ }^{35}$ to determine the electronic structure of the synthesized dyes. The geometries for each molecule was obtained from the initial guess structure and optimized fully by the DFT in the gas state within the B3LYP hybrid exchange correlation functional and 6-311G basis set. Computationally calculated frontier molecular orbital diagrams in ground state for 1-5 are shown in Figure 4.

We would like to point out here that even though the formal density functional theory is exact, the formalism given by Kohn-Sham (KS) makes the KS orbital energies more mathematical than physical. However, 

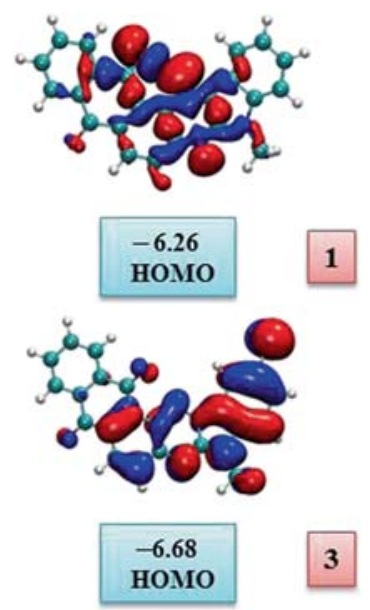
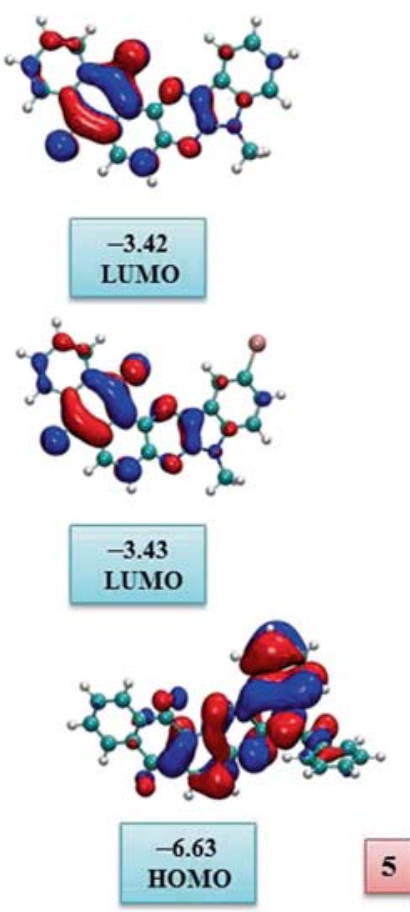
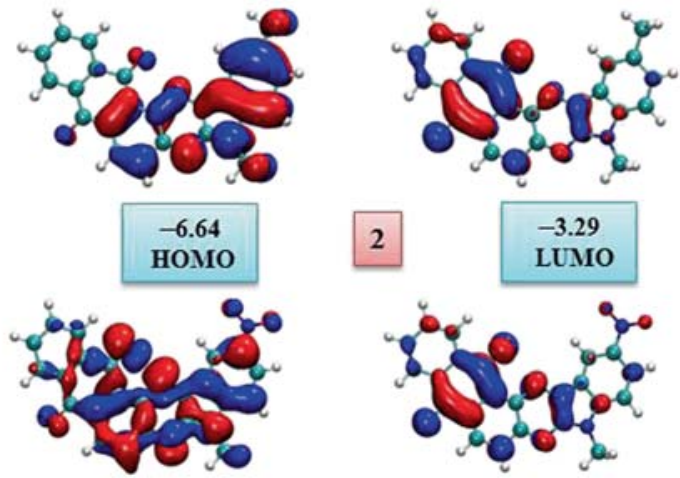

LUMO

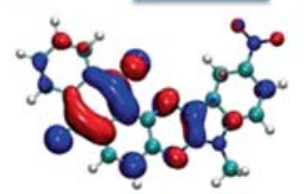

$-6.51$ HOMO

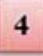

$-3.39$ LUMO

Figure 4. Schematic representation of theoretically calculated frontier molecular orbitals of compounds 1-5.

it may be noted that this method has been applied to a large variety of problems starting from simple molecules to large molecules and extended systems. ${ }^{12 \mathrm{~b}, 22}$ To test the effect of basis set, we have also carried out calculation for all the molecules with an enhanced basis set $6-311+\mathrm{G}^{*}$ which includes one diffuse function and one polarization function. The HOMO, LUMO values as well as the HOMO-LUMO gap are within $5 \%$ of those computed by the $6-311 \mathrm{G}$ basis which are within the accuracy of the density functional methods. The values for HOMO, LUMO energies for these two basic functions are given in Supplementary Information.

HOMO orbital of 1-5 are found to be spread through out the indoloquinoxaline segment. While LUMO orbitals are mainly on the benzoquinone and partially on quinoxaline moiety. The location of HOMO/LUMO in 1-5 suggest an in-built donor-acceptor couple for the dyes, commonly observed for molecules having donor-acceptor architecture and indicates the reason for the appearance of prominent ICT peak in the absorption spectra. The effect of substitution in DFT studies was seen as alteration of the HOMO orbitals in the molecules. In compounds $\mathbf{2 - 4}$, HOMO molecular orbitals are found to reside over entire indoloquinoxaline segment and also on the substituent attached to the indole unit. Whereas, in compound $\mathbf{1}$ with no substitution, HOMO orbitals were mainly confined over quinoxaline and pyrrole ring while benzene ring of indole unit does not bear any HOMO orbitals. However, substitution to indoloquinoxaline segment was not found to alter the LUMO orbitals of the molecules.

The values of ionization potential and electron affinity were determined using vertical parameters. The first ionization potential and the electron affinity has been computed by the following method; the electron affinity (EA) is computed as:

$$
\mathrm{EA}=-\left(\mathrm{E}_{\text {neutral }}-\mathrm{E}_{\text {anion }}\right)
$$

and the ionization potential (IP) is computed as:

$$
\mathrm{IP}=\left(\mathrm{E}_{\text {neutral }}-\mathrm{E}_{\text {cation }}\right)
$$

Where, $\mathrm{E}_{\text {neutral }}, \mathrm{E}_{\text {anion }}$ and $\mathrm{E}_{\text {cation }}$ are the energies of neutral, anionic and cationic forms of the molecule.

The energies of the HOMO and LUMO levels, HOMO-LUMO gap, first ionization potential, electron affinity and ground-state dipole moment were computed for the dyes 1-5 and collected in Table 3. The HOMO and LUMO energy level of the compounds occur in the ranges of -6.11 to -6.81 and -3.22 to $-3.56 \mathrm{eV}$, respectively, and are in close agreement with those calculated using CV data. The theoretically calculated low lying LUMO values support experimental data and thus, these compounds may be effective as electron-transport layer and can be used as n-type materials for optoelectronic devices. The energy band gaps for the dyes are found in the range of $2.89-3.25 \mathrm{eV}$. The dipole moment calculated for $\mathbf{1 - 5}$ in gas phase are small but it was found to be higher for compound $4(5.85 \mathrm{eV})$ 
Table 3. Computed Ionization potential, Electron affinity, HOMO-LUMO energy levels, Energy band gap and Dipole moment of 1-5.

\begin{tabular}{lcccccc}
\hline Compound & $\mathrm{I}_{\mathrm{p}}(\mathrm{eV})$ & $\mathrm{E}_{\mathrm{a}}(\mathrm{eV})$ & $\mathrm{E}_{\mathrm{HOMO}}(\mathrm{eV})$ & $\mathrm{E}_{\mathrm{LUMO}}(\mathrm{eV})$ & $\mathrm{E}_{\mathrm{g}}(\mathrm{eV})$ & Dipole (debye) \\
\hline $\mathbf{1}$ & 7.62 & 1.89 & -6.26 & -3.25 & 3.01 & 3.73 \\
$\mathbf{2}$ & 7.47 & 1.86 & -6.11 & -3.22 & 2.89 & 4.10 \\
$\mathbf{3}$ & 7.66 & 2.03 & -6.34 & -3.37 & 2.97 & 3.33 \\
$\mathbf{4}$ & 8.09 & 2.26 & -6.81 & -3.56 & 3.25 & 5.85 \\
$\mathbf{5}$ & 7.55 & 1.92 & -6.26 & -3.26 & 3.01 & 3.71 \\
\hline
\end{tabular}

as compared to other derivatives due to presence of polar $-\mathrm{NO}_{2}$ group attached to indole segment. We have also computed the frequencies for all the molecules and found that all the frequencies are real and positive (see Supplementary Information).

\section{Conclusions}

We have synthesized a series of five indolo[2,3- $b$ ] quinoxaline dyes derived from anthraquinone by cyclocondensation reactions in good yield. The compounds were thoroughly analyzed by routine spectral methods and subjected to photophysical, electrochemical, thermal and computational studies. These dyes show strong solvent-dependent photophysical properties and large fluorescence red shifts upon passing from non-polar to polar solvents and protic solvents at room temperature. A broad absorption band observed in lower energy is attributed to in-built intramolecular charge transfer transition. All compounds were found to emit in the range of 580-648 $\mathrm{nm}$ in solution and in red region in the range $672-700 \mathrm{~nm}$ in neat solid film. Electrochemical studies reveal the stability of these compounds under redox conditions. These molecules were found to have low-lying LUMO energy levels in the range of -3.29 to $-3.43 \mathrm{eV}$ which are very similar with commonly used n-type materials. These findings indcate that the synthesized dyes have potential to be useful as electron-transport materials in optoelectronic devices. We are currently working in the direction of developing organic dyes containing napthoquinone-indoloquinoxaline segment suitable for applications in excitonic solar cells and other organic electroactive devices.

\section{Supplementary Information (SI)}

All the additional details pertaining to the characterization of the compounds 1-5 using ${ }^{1} \mathrm{H}$ and ${ }^{13} \mathrm{C}$-NMR spectra (Figures S1-S4), MALDI-TOF (Figures S5-S9), mass spectra, FTIR spectra (Figures S10-S14), Photophysical data in various solvents (Tables S1-S5), Absorption and emission spectra in various solvents and in neat solid film (Figures
S15-S20), Cyclic voltammetry and differential pulse voltammetry results (Figures S21-S25), Thermo-Gravimetric (TG), Derivative weight loss and Differential Scanning Calorimetry plots (Figure S26-S30), Optimized structures (Figures S31-S35) with their Cartesian coordinates and the computed frequencies for all molecules with 6-311G and the HOMO-LUMO values of the molecules for two different basis sets are given in the Supporting Information. Supplementary Information is available at www.ias.ac.in/ chemsci.

\section{Acknowledgements}

Financial support from the Science and Engineering Research Board (DST-SERB), New Delhi, India [SERB Scheme No. SB/EMEQ-507/2014] is gratefully acknowledged. BKS and AMS thank the University Grant Commission, India for research fellowships. We thank the Micro-Analytical Laboratory, Department of Chemistry, University of Mumbai and UM-DAE Centre for Excellence in Basic Sciences, Mumbai for providing instrumentation facility. We also thank the Tata Institute of Fundamental Research, Mumbai for MALDI-TOF and ${ }^{1} \mathrm{H}$ NMR facilities.

\section{References}

1. (a) Baldo $\mathrm{M}$ A, Thompson $\mathrm{M} \mathrm{E}$ and Forrest $\mathrm{S} \mathrm{R}$ 2000 High-efficiency fluorescent organic light-emitting devices using a phosphorescent sensitizer Nature $\mathbf{4 0 3}$ 750; (b) Friend R H, Gymer R W, Holmes A B, Burroughes J H, Marks R N, Taliani C, Bradley D D C, Dos Santos D A, Bredas J L, Lögdlund M and Salaneck W R 1999 Electroluminescence in conjugated polymers Nature 397121

2. (a) Brütting W, Berleb S and Mückl A G 2001 Device physics of organic light emitting diodes based on molecular materials Org. Electron. 2 1; (b) Anthony J E 2008 The larger acenes: Versatile organic semiconductors Angew. Chem. Int. Ed. 47452

3. (a) Imahori H, Umeyama $\mathrm{T}$ and Ito $\mathrm{S} 2009$ Large piaromatic molecules as potential sensitizers for highly efficient dye-sensitized solar cells Acc. Chem. Res. 42 1809; (b) Ning Z and Tian H 2009 Triarylamine: A promising core unit for efficient photovoltaic materials Chem. Commun. 414 5483; (c) Grätzel M 2009 
Recent Advances in sensitized Mesoscopic Solar Cell Acc. Chem. Res. 421788

4. (a) Meng H, Sun F, Goldfinger M B, Jaycox G D, Li Z, Marshall W J and Blackman G S 2005 HighPerformance, Stable Organic Thin-Film Field-Effect Transistors Based on Bis-5'-alkylthiophen-2'-yl-2,6anthracene Semiconductors J. Am. Chem. Soc. 127 2406; (b) Chung D S, Park J W, Park J-H, Moon D, Kim G H, Lee H-S, Lee D H, Shim H-K, Kwon S-K and Park C E 2010 High mobility organic single crystal transistors based on soluble triisopropylsilylethynyl anthracene derivatives J. Mater. Chem. 20 524; (c) Teng C, Yang X, Yang C, Li S, Cheng M, Hagfeldt A and Sun L 2010 Molecular Design of Anthracene-Bridged Metal-Free Organic Dyes for Efficient Dye-Sensitized Solar Cells. J. Phys. Chem. C 1149101

5. (a) Ihmels H, Meiswinkel A and Mohrschladt C J 2000 Novel fluorescence probes based on 2,6-donoracceptor-substituted anthracene derivatives Org. Lett. 2 2865; (b) Wasserman H H, Scheffer J R and Cooperb J L 1972 Singlet Oxygen Reactions with 9,1ODiphenylanthracene Peroxide J. Am. Chem. Soc. 94 4991

6. (a) Forrest S R 2004 The path to ubiquitous and lowcost organic electronic appliances on plastic Nature $\mathbf{4 2 8}$ 911; (b) Kaltenbrunner M, White M S, Glowacki E D, Sekitani T, Someya T, Sariciftci N S and Bauer S 2012 Ultrathin and lightweight organic solar cells with high flexibility Nat. Commun. 3 770; (c) Kippelen B and Brédas J-L 2009 Organic photovoltaics Energy Environ. Sci. 2 251; (d) Li G, Zhu R and Yang Y 2012 Polymer solar cells Nat. Photonics. 6 153; (e) Søndergaard R, Markus H, Dechan A, Thue T L-O and Krebs F C 2012 Roll-to-Roll Fabrication of Polymer Solar Cells Mat. Today 15 36; (f) Su Y-W, Lan S-C and Wei K-H 2012 Organic photovoaltics Mat. Today 15554

7. (a) Darling S B and You F 2013 The case for organic photovoltaics RSC Adv. 3 17633; (b) Marzano G, Ciasca C V Babudri F, Bianchi G, Pellegrino A, Po R et al. 2014 Organometallic approaches to conjugated polymers for plastic solar cells: From laboratory synthesis to industrial production. European J. Org. Chem. 2014 6583

8. (a) Jenekhe S A, Lu L, Alam M M 2001 New Conjugated Polymers with Donor - Acceptor Architectures: Synthesis and Photophysics of Carbazole Quinoline and Phenothiazine - Quinoline Copolymers and Oligomers Exhibiting Large Intramolecular Charge Transfer Macromolecules 34 7315; (b) Tao S, Li L, Yu J, Jiang Y, Zhou Y, Lee C-S, Lee S-T, Zhang X and Kwon O 2009 Bipolar molecule as an excellent holetransporter for organic-light emitting devices Chem. Mater. 21 1284; (c) Lee B-L and Yamamoto T 1999 Syntheses of New Alternating CT-Type Copolymers of Thiophene and Pyrido[3,4- $b]$ pyrazine Units: Their Optical and Electrochemical Properties in Comparison with Similar CT Copolymers of Thiophene with Pyridine and Quinoxaline Macromolecules 321375

9. (a) Jenekhe S A and Yi S 2000 Highly Photoconductive Nanocomposites of Metallophthalocyanines and
Conjugated Polymers Adv. Mater. 12 1274; (b) Kohler A, Dos Santos D A, Beljonne D, Shuai Z, Bredas J L, Holmes A B, Kraus A, Mullen K and Friend R H 1998 Charge separation in localized and delocalized electronic states in polymeric semiconductors Nature 392 903

10. (a) Kraft A, Grimsdale A and Holmes A B 1998 Electroluminescent conjugated polymer-seeing polymers in a new light Angew Chem. Int. Ed. 37 402; (b) Cui Y, Zhang X and Jenekhe S A 1999 Thiophene-Linked Polyphenylquinoxaline: A New Electron Transport Conjugated Polymer for Electroluminescent Devices Macromolecules 323824

11. Schon J H, Kloc C, Dodabalapur A and Batlogg B 2000 An organic solid state injection laser Science 289599

12. (a) Sharma B K, Shaikh A M, Agarwal N and Kamble R M 2016 Synthesis, photophysical and electrochemical studies of acridone-amine based donor-acceptors for hole transport materials $R S C A d v .6$ 17129; (b) Shaikh A M, Sharma B K, Chacko S and Kamble R M 2016 Synthesis and optoelectronic investigations of triarylamines based on naphtho[2,3- $f$ ]quinoxaline-7,12dione core as donor-acceptors for n-type materials $R S C$ Adv. 660084

13. Yang C-J, Jenekhe S A, Meth J S and Vanherzeele H 1999 Probing structure-property relationships in third-order nonlinear optical polymers: Third harmonic generation spectroscopy and theoretical modeling of systematically derivatized conjugated aromatic polyimines Ind. Eng. Chem. Res. 381759

14. (a) Sharma B K, Shaikh A M and Kamble R M 2015 Synthesis, photophysical, electrochemical and thermal investigation of Triarylamines based on 9H-Xanthen-9one: Yellow-green fluorescent materials J. Chem. Sci. 127 2063; (b) Shaikh A M, Sharma B K and Kamble R M 2015 Synthesis, Photophysical, Electrochemical and Thermal Studies of Triarylamines based on benzo[g]quinoxalines J. Chem. Sci. 1271571

15. (a) Agarwal N, Nayak P K, Ali F, Patankar M P, Narasimhan K L and Periasamy N 2011 Tuning of HOMO levels of carbazole derivatives: New molecules for blue OLED Synth. Met. 161 466; (b) Montes V A, Perez-Bolivar C Agrawal N, Shinar J and Anzenbacher P 2006 Molecular-Wire Behaviour of OLED Materials: Exciton Dynamics in Multichromophoric $\mathrm{Alq}_{3}$ Oligofluorene-Pt(II)porphyrin Triads $J$. Am. Chem. Soc 12812436

16. (a) Harmenberg J, Wahren B, Bergman J, Akerfeldt $\mathrm{S}$ and Lundlad L 1988 Antiherpesvirus activity and mechanism of action of indolo-[2,3- $b$ ]quinoxaline and analogs Antimicrob. Agents Chemother. 32 1720; (b) Harmenberg A, Malmfors G T, Bergman J, Wahren B and Cox S 1991 The mechanism of action of the anti-herpes virus compound 2,3-dimethyl-6(2-dimethylaminoethyl)-6H-indolo-[2,3-b]quinoxaline Antiviral Res. 15193

17. (a) Hirata J, Araya S, Nakaike K K and Ishida T 2001 Side Chain - Dependent Binding of Antitumor Indoloquinoxaline Derivatives to DNA: Comparative Spectroscopic and Viscometric Measurements Chem. Pharm. Bull. 49 44; (b) Deady L W, Kaye A J, Finlay G J, Baguley B C and Denny W A 1997 Synthesis and 
antitumor properties of N-[2-(dimethylamino)ethyl]carboxamide derivatives of fused tetracyclic quinolines and quinoxalines: A new class of putative topoisomerase inhibitors. J. Med. Chem. $\mathbf{4 0} 2040$

18. Manna K and Agrawal Y K 2009 Microwave assisted synthesis of new indophenazine 1,3,5-trisubstruted pyrazoline derivatives of benzofuran and their antimicrobial activity Bioorganic Med. Chem. Lett. 192688

19. Pai N R and Pusalkar D A 2010 Pharmacological screening of novel indolo [2,3-b] quinoxaline derivatives $J$. Chem. Pharm. Res. 2485

20. (a) Przyjazna B, Kucybała Z and Pa̧czkowski J 2004 Development of new dyeing photoinitiators based on 6H-indolo[2,3-b] quinoxaline skeleton Polymer 45 2559; (b) Waluk J and Komorowski S J 1986 Solvent depedndentphotophysics of indoloquixaline J. Molec. Strut. 142159

21. (a) Waluk J and Komorowski S J 1987 Modification of photophysical behaviour by hydrogen bonding: Indoloquinoxaline and its methylated derivatives Chem. Phys. Lett. 133 368; (b) Waluk J and Thulstrup E W 1988 Excited states of indoloquinoxalines Spectrochim. Acta, Part A 441335

22. (a) Thomas K R J and Tyagi P 2010 Synthesis, spectra, and theoretical investigations of the triarylamines based on 6H-indolo[2,3-b] quinoxaline J. Org. Chem. 75 8100; (b) Shaikh A M, Sharma B K and Kamble R M 2015 Photophysical, Electrochemical and Thermal Studies of 5-methyl-5H-Benz $[g]$ indolo[2,3- $b]$ quinoxaline Derivatives: Green and Yellow Fluorescent Materials Can. Chem. Trans. 3 158; (c) Payne A-J, McCahill J S J and Welch G C 2015 Indoloquinoxaline as a terminal building block for the construction of $\pi$-conjugated small molecules relevant to organic electronics Dyes Pigm. 123 139; (d) Tyagi P, Venkateswararao A and Thomas K R J 2011 Solution processable indoloquinoxaline derivatives containing bulky polyaromatic hydrocarbons: Synthesis, optical spectra, and electroluminescence J. Org. Chem. 76 4571; (e) Qian X, Gao H, Zhu Y, Lu L and Zheng J $20156 \mathrm{H}$-Indolo [2,3-b] quinoxaline-based organic dyes containing different electron-rich conjugated linkers for highly efficient dye-sensitized solar cells J. Power Sources 280 573; (f) Venkateswararao A, Tyagi P, Thomas J K R, Chen P W and Ho K C 2014 Organic dyes containing indolo[2,3-b]quinoxaline as a donor: Synthesis, optical and photovoltaic properties. Tetrahedron 70 6318; (g) Qian X, Wang X, Shao L, Li H, Yan R and Hou L 2016 Molecular engineering of D-D-A type organic dyes incorporating indoloquinoxaline and phenothiazine for highly efficient dye-sensitized solar cells J. Power Sources 326129

23. Ormond A B and Freeman H S 2013 Effects of substituents on the photophysical properties of symmetrical porphyrins Dyes Pigm. 96440

24. (a) Tarek A, Fayzah A B-J and Omima A W 2010 Shiff bases of indoline-2,3-dione (isatin) derivatives and nalidixic acid carbohydrazide, synthesis, antitubercular activity and pharmacophoric model building Eur. J. Med. Chem. 45 4578; (b)Beauchard A, Ferandin Y, Frère $\mathrm{S}$, Lozach O, Blairvacq M, Meijer L, Thiéry V and Besson T 2006 Synthesis of novel 5-substituted indirubins as protein kinases inhibitors Bioorg. Med. Chem. 146434
25. Thomas $\mathrm{K}$ R J, Lin $\mathrm{J} \mathrm{T}$, Tao $\mathrm{Y} \mathrm{T}$ and Chuen $\mathrm{C} \mathrm{H}$ 2004 New carbazole-oxadiazole dyads for electroluminescent devices: Influence of acceptor substituents on luminescent and thermal properties Chem. Mater. 16 5437

26. (a) Shaikh A M, Sharma B K and Kamble R M 2016 Synthesis and opto-electrochemical properties of tribenzo[ $a, c, i]$ phenazine derivatives for hole transport materials RSC Adv. 6 94218; (b) Jandke M, Strohriegl P, Berleb S, Werner E and Brutting W 1998 Phenylquinoxaline polymers and low molar mass glasses as electrontransport materials in organic light-emitting diodes Macromolecules 316434

27. Ajloo D, Yoonesi B and Soleymanpour 2010 Solvent effect on the reduction potential of anthraquinones derivatives. The experimental and computational studies Int. J. Electrochem. Sci. 5459

28. (a) Schulz G L, Kar P, Weidelener M, Vogt A, Urdanpilleta M, Lindén M, Meena-Osteritz E, Mishra A and Bäuerle P 2016 The influence of alkyl side chains on molecular packing and solar cell performance of dithienopyrrole-based oligothiophenes J. Mater. Chem. A 4 10514; (b) Cekli S, Winkel R W, Alarousu E, Mohammed O F and Schanze K S 2016 Triplet excited state properties in variable gap $\pi$-conjugated donor-acceptor-donor chromophores Chem. Sci. 73621

29. (a) Kulkarni A P, Tonzola C J, Babel A and Jenekhe S A 2004 Electron transport materials for organic lightemitting diodes Chem. Mater. 16 4556; (b) Usta H, Facchetti A and Marks T J 2011 n-Channel Semiconductor Materials Design for Organic Complementary Circuits Acc. Chem. Res. 44 501; (c) Gao X and Hu Y 2014 Development of $n$-type organic semiconductors for thin film transistors: A viewpoint of molecular design J. Mater. Chem. C 2 3099; (c) Wang Z, Kim C, Facchetti A and Marks T J 2007 Anthracenedicarboximides as air-stable $\mathrm{N}$-channel semiconductors for thin-film transistors with remarkable current onoff ratios J. Am. Chem. Soc. 129 13362; (d) Jones B A, Facchetti A, Wasielewski M R and Marks T J 2007 Tuning Orbital Energetics in AryleneDiimide Semiconductors. Materials Design for Ambient Stability of $n$-Type Charge Transport J. Am. Chem. Soc. 56 15259

30. Tang C W and VanSlyke S A 1987 Organic electroluminescent devices Appl. Phys. Lett. 51913

31. Tonzola C J, Alam M M, Kaminsky W and Jenekhe S A 2003 New n-type organic semiconductors: Synthesis, single crystal structures, cyclic voltammetry, photophysics, electron transport, and electroluminescence of a series of diphenylanthrazolines J. Am. Chem. Soc. 125 13548

32. Tabatake S, Naka S, Okada H, Onnagawa H, Uchida M, Nakano T and Furukawa K 2002 Low operatinal voltage of electroluminescent devices with a high bipolar conducting silole derivative Jpn. J. Appl. Phys. 416582

33. Fukuda T, Kanbara T, Yamamoto T, Ishikawa K, Takezoe H and Fukuda A 1996 Polyquinoxaline as an excellent electron injecting material for electroluminescent device Appl. Phys. Lett. 682346 
34. (a) O'Brien $\mathrm{D}$, Weaver $\mathrm{M}$ S, Lidzey $\mathrm{D}$ G and Bradley D D C 1996 Use of poly(phenyl quinoxaline) as an electron transport material in polymer light-emitting diodes Appl. Phys. Lett. 69 881; (b) Cui Y, Zhang X and Jenekhe S A 1999 Thiophene-Linked
Polyphenylquinoxaline: A New Electron Transport Conjugated Polymer for Electroluminescent Devices Macromolecules 323824

35. Frisch M J et al. 2004 Gaussian 03, Revision E.01, Gaussian, Inc., Wallingford CT 